\title{
From the floor
}

$-$ 


\title{
Convergence and Soniculture: 10 Years of MUTEK
}

\author{
TOBIAS C. VAN VEEN \\ MCGILL UNIVERSITY (CANADA)
}

from

the

floor

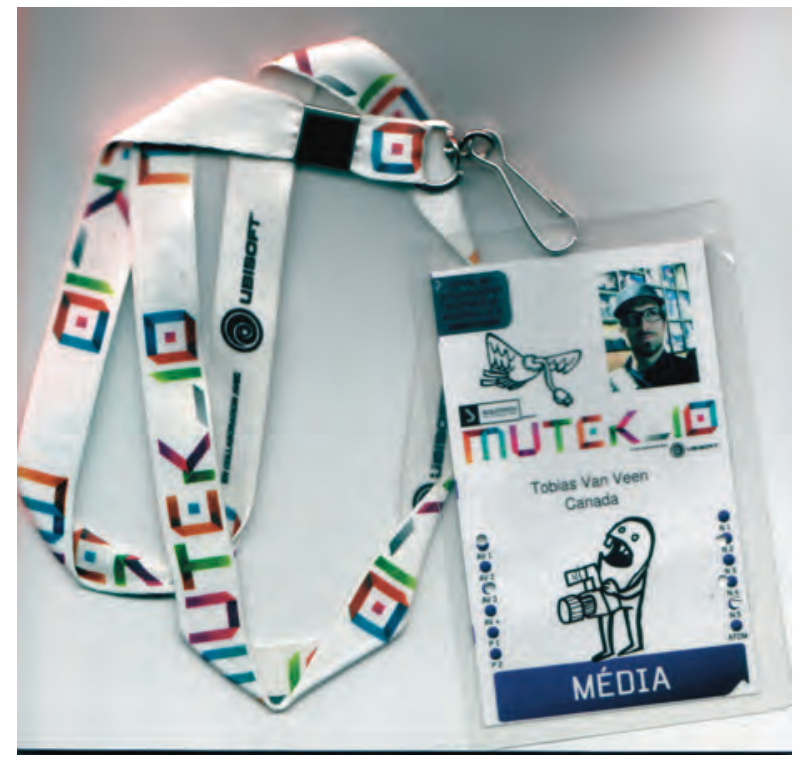

When considering electronic dance music culture (EDMC) - not as an object of study in the world, but as a description, a concept itself - the variables of the phrase come under some pressure. Need EDMC be electronic, as if electrons alone define the production aesthetic, "made by electricity"? Or need the electron signal the sound, as the 1990s defined quasi-genre "electronica" suggests by way of its inaccuracy (what recorded music isn't electronic in the 21C)?! And need EDMC be dance music, insofar as such a distinction would exclude prone modes of body listening found everywhere, in ambient music chill rooms, as well as the focused attention of the elongated ear to be found at contemporary experimental music performances from microsound to noise? And, in the case of noise, or other frequency experimentation, including the use of all-sound or silence - and one thinks here of the lasting influence of John Cage in experimental electronic music from embracing percussion as the means to all-sound to random chance operations to improvisation ${ }^{2}$ - can we say that sonic experimentation need be conceptualised as music? In what sense? Finally, what bounds the three signifiers above into a culture? 


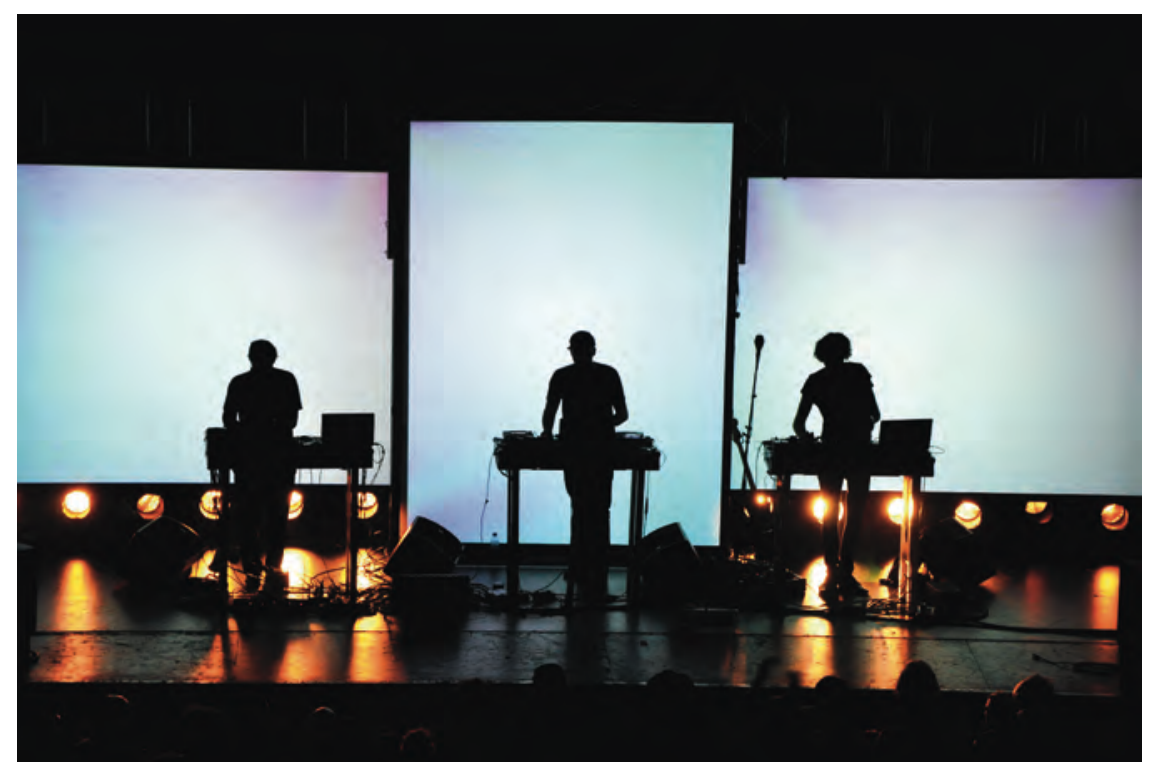

The seated \& the danced: Moderat @ MUTEKX (2009).Photo: tobias c.van Veen

In short, if an event combines both prone postures and dancing dervishes, as well as two forms of nonmusic, rhythmic and arhythmic, noise and silence, in an approximation that is only "electronic" insofar as everything amplified and recorded is electronic (and thus the signifier is banal), is there an electronic dance music culture if "dance" and "music" remain as secondary to the diversity of approaches such an event would attempt to contain? Or would not contain, nor constrain - would not the culture exist only in its inversion, turning itself inside-out, a culture of its outsides? And can we analyse such an event under the descriptive "alphabet talk" - to sample William Gibson ${ }^{3}$ - of EDMC?

All of which would be a way to introduce MUTEK, ${ }^{4}$ which in 2009 celebrated its 10th anniversary. MUTEK takes place in Montréal, a city that has branded itself in the worldwide tourism industry as the "city of festivals", 5 with its Jazz Festival, Just For Laughs comedy festival, and so on. ${ }^{6}$ And so MUTEK came into being under the operating paradigm of Tourism Montréal's annual barrage of festivities: a multi-day extravaganza exploring the nether reaches of electronic but also experimental dance and sometimes not dance music (nor sometimes even music), and if need be appended, culture (but also just a lot of ridiculous partying, writhing, scenestering, mulling around and drinking - the culture of the urban electronite).

\section{http://vimeo.com/4929374}

Mutek 10 en 1 minute from Anne-Marie Bergeron

MUTEK was conceived by media arts curators Alain Mongeau and Eric Mattson in 1999 as a way to address what they saw as a soniculture no longer that of rave culture, yet distinct from the New Media arts they curated at the time for the Montreal International Festival of New Cinema and New Media (FCMM). ${ }^{7}$ The operational portmanteau of soniculture - a convergence of aesthetic explorations in sonics that, through its convergence, establishes a social network - works well to describe the impetus behind MUTEK. What Mongeau and Mattson observed was a post-rave, 
post-new media scene exploring the sonics of experimental electronic music without need to either subject it to the functionalism required of rave-era electronic music, on the one channel, nor the strict historicist confines of an aesthetically straight-jacketed institutional arts practice on the other, thus developing avenues of sonic and visual production in which the potential for a convergence, a culture, began to flower. ${ }^{8}$

\section{http://www.youtube.com/watch?v=KhSXr6DW6bE}

\section{XLR8R TV Ep. 67: MUTEK Grows Older \& Wiser. Video: tobias c. van Veen and Ken Taylor}

Since its inception in 2000, MUTEK has showcased variants of electronic music that were, for the most part, outside the club and rave circuits as well as those of media arts, and as one would expect, focused on experimental directions in beatless approaches such as ambient, microsound, noise and other abstract compositional strategies, always on the verge of academic, institutional electro-acoustic or acousmatic music but maintaining the urgency of non-institutional DiY aesthetics. Yet what set MUTEK apart from the point-of-view of the New Media arts scene was its dedication to hearing rhythmic, beat-punctuated and percussive electronic music as a serious art form. MUTEK provided a space that was neither rave nor club, neither new media lounge nor electro-acoustic concert. Its early events in unseated, open-spaces such as the Society for Arts and Technology (SAT) ${ }^{9}$ and Ex-Centris's Salle ${ }^{10}$ were notorious for eschewing seating as well as any traditional sense of flow, at least in the rave-era expectation of a sonic trajectory leading up to the climax and dénouement, insofar as the evening might shift from beats to noise, microsound to dub, with no particular aesthetic order governing the lineup (though early editions focused on label showcases, and certain themes, the timing of the artists remained unconventional). To this extent, the early editions often challenged the audience's sense of direction, and in response, rarely did an audience get up (or get down) and dance. In fact, at some events an odd mixture of standing / sitting / dancing / mixing took place, a subtle but characteristic confusion of bodies unsettled by space and sound.

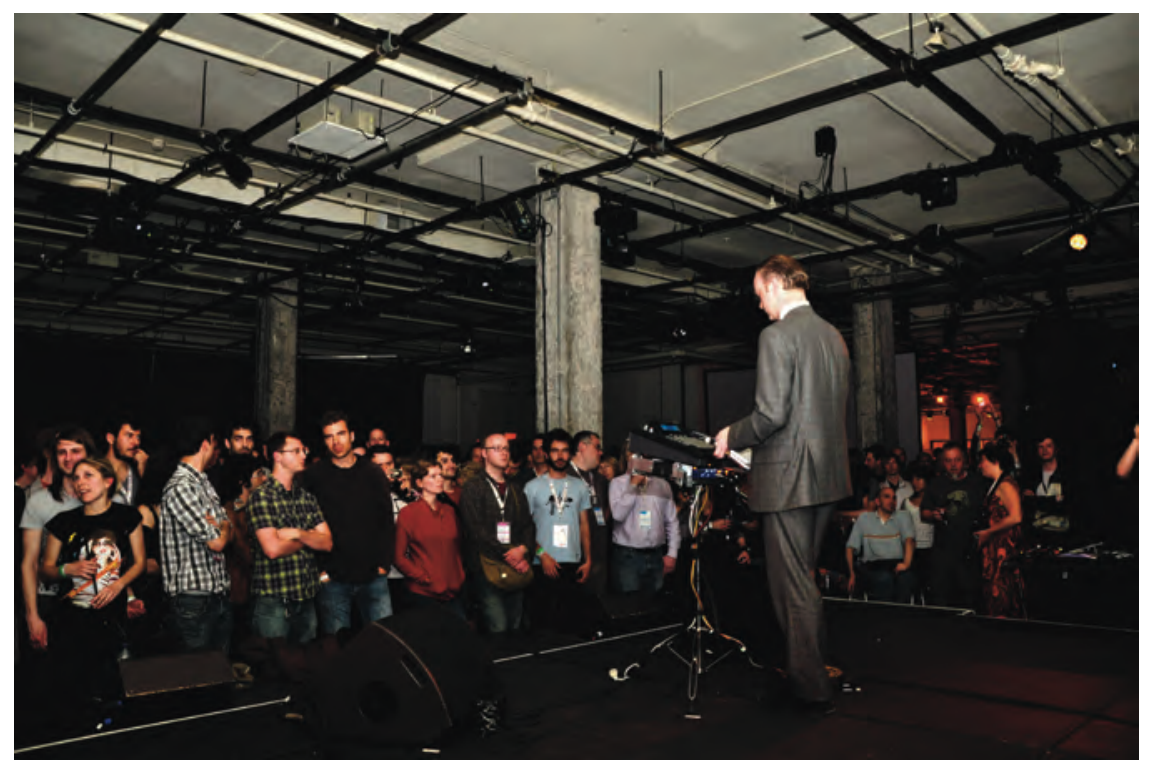

Standing room only: Atom Heart plays SAT, MUTEKX (2009). Photo: tobias c. van Veen 
To this extent, MUTEK developed a reputation as a straightlaced festival, even (wrongly) an academic one, a representation which persisted even as MUTEK strove to embrace a sonic aesthetic of hedonist and ecstatic release (and ironically, later embracing artists with academic credentials). Mongeau commented upon the self-generated gravitas of MUTEK in 2008:

We kind of perceived the festival as a digital culture festival. The way the festival was established was perceived as such a serious event. And I think that's a bit our fault - or it's actually an achievement, as we wanted to distinguish the festival from the club and the rave culture, so we had to give it kind of an envelope of being something that could be taken seriously. And we managed so well that actually we scared a lot of people away.11

This all-too-serious representation was still at play in 2008, as evident in the surprised reaction of sampladelic turntablist and producer Kid Koala to playing a Friday night MUTEK gig at Metropolis: "I was under the impression it was a very, yah, sort of academic crowd, but that night it was just a big party, really, y'know..." ${ }^{12}$

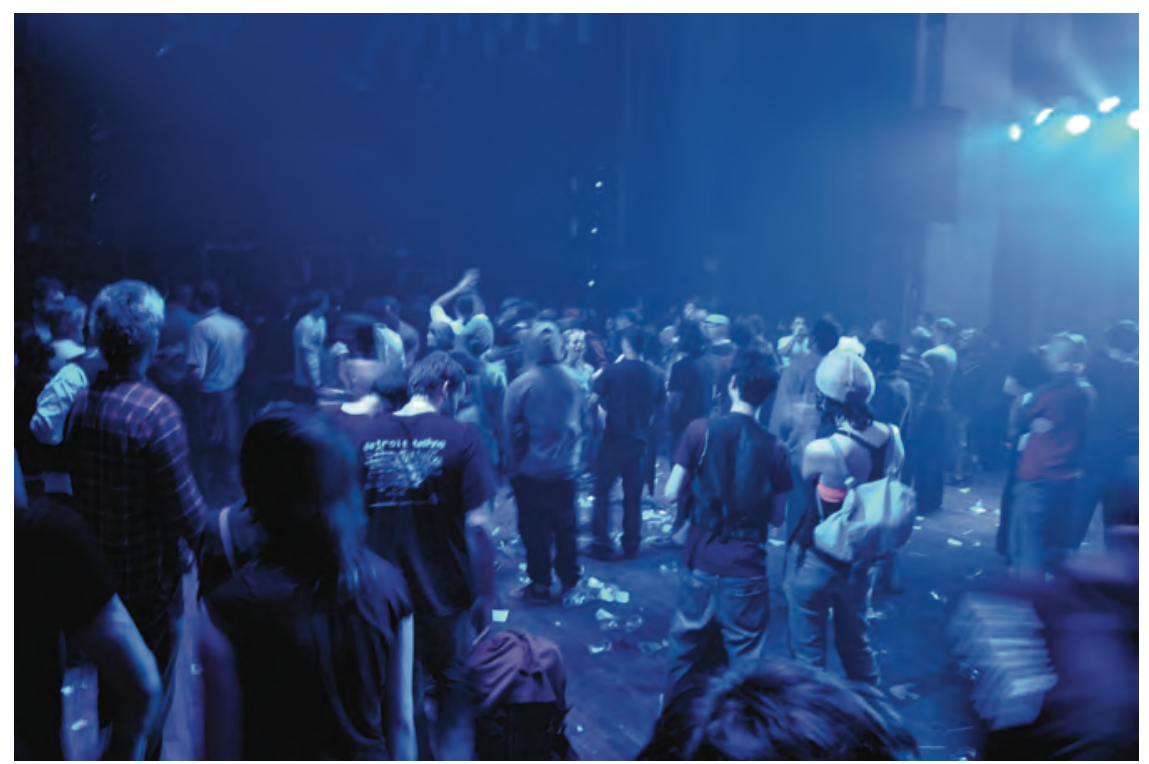

Dancefloor detritus: all that is left after Mala destroys the crowd with dubstep, MUTEKX (2009). Photo: tobias c. van Veen

But in the distant past of 2002, only on the Sunday and last night of the festival would the curtains drop and the beats repeat until dawn, embracing the euphoria of letting loose to endless hours of repetitive rhythm, as something of MUTEK's attempt to play at being serious was dropped like the strangely absent needle on the turntable - as at the time MUTEK rarely acknowledged the role of the techno-turntablist in EDMC, choosing to focus near exclusively on non-turntablist performance. It was something of the absence of the turntablist that led to the lack of the festival's flow. ${ }^{13}$ Yet, at this hazy moment of persistent rhythm, the serious came through in the fray of the music's relentlessness: a new flow was being pioneered in the improvisation of electronic gear. 
As Philip Sherburne observed at the time, this moment where the "crowd heaved in unison" as the "brushed aluminum and bubble wrap" of "aerated minimalism" dropped away, the "cushioned" and "lacking bite" microhouse giving itself over to a music that "was so aggressively present that it became possible to forget it was there at all - it simply was" (Sherburne 2002). And I know - I was there at the time, writing furiously on a notepad under the gear table as Ricardo Villalobos, Dandy Jack and Atom Heart jammed above me, only to realise someone else had crawled into this mess of wires and bass reverberations - it was Philip, who goes on:

For an hour, two, more, they played groove off of groove, wrapping disparate rhythms around each other, sparking a magnetic field that held the entire audience spellbound. This - now this was something. Something I'd never heard before, a whole new kind of electronic music. But there was no time to think about it then. This tidal ebb and flow went on for hours, literally hours, building an impossible tension. The crowd was enraptured, lost in one of those moments of total communion. The club, which was supposed to close at 3 a.m., kept going until 5, drawing black velvet curtains against the sunrise outside.

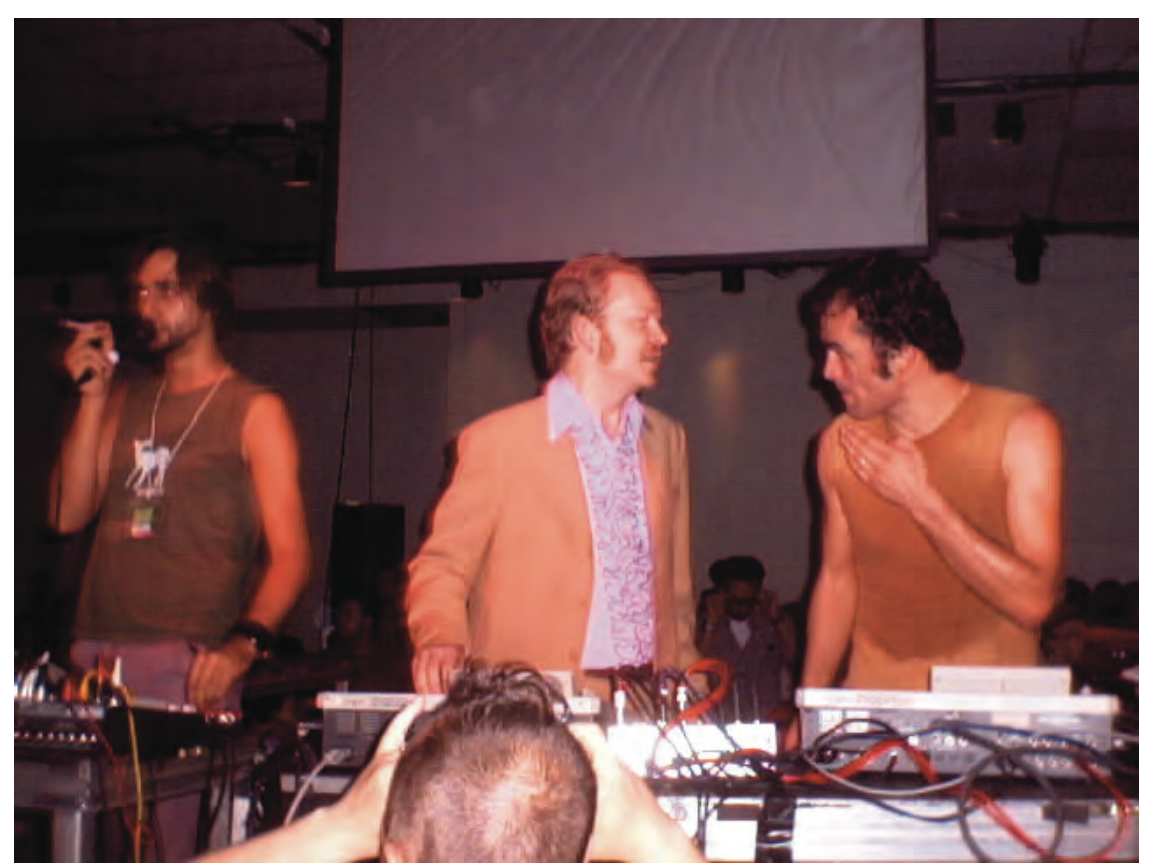

The birth of minimal: Ricardo Villalobos, Atom Heart, Dandy Jack in the old SAT, MUTEK 2002. Photo: tobias c. van Veen

To resample Philip's observation - which I also made at the time ${ }^{14}$ - a new electronic music sound had been birthed as Atom Heart, Dandy Jack and Ricardo Villalobos manually synchronized their gear without MIDI, a raw minimalism in which "The rhythm swirled around and around in a self-canceling moment of equatorial confusion where clockwise and counterclockwise collide". In short, when MUTEK dropped its pants and lost itself, it birthed a new genre: what was to become known as minimal or $\mathrm{k}$-house (we'll get to this below). 


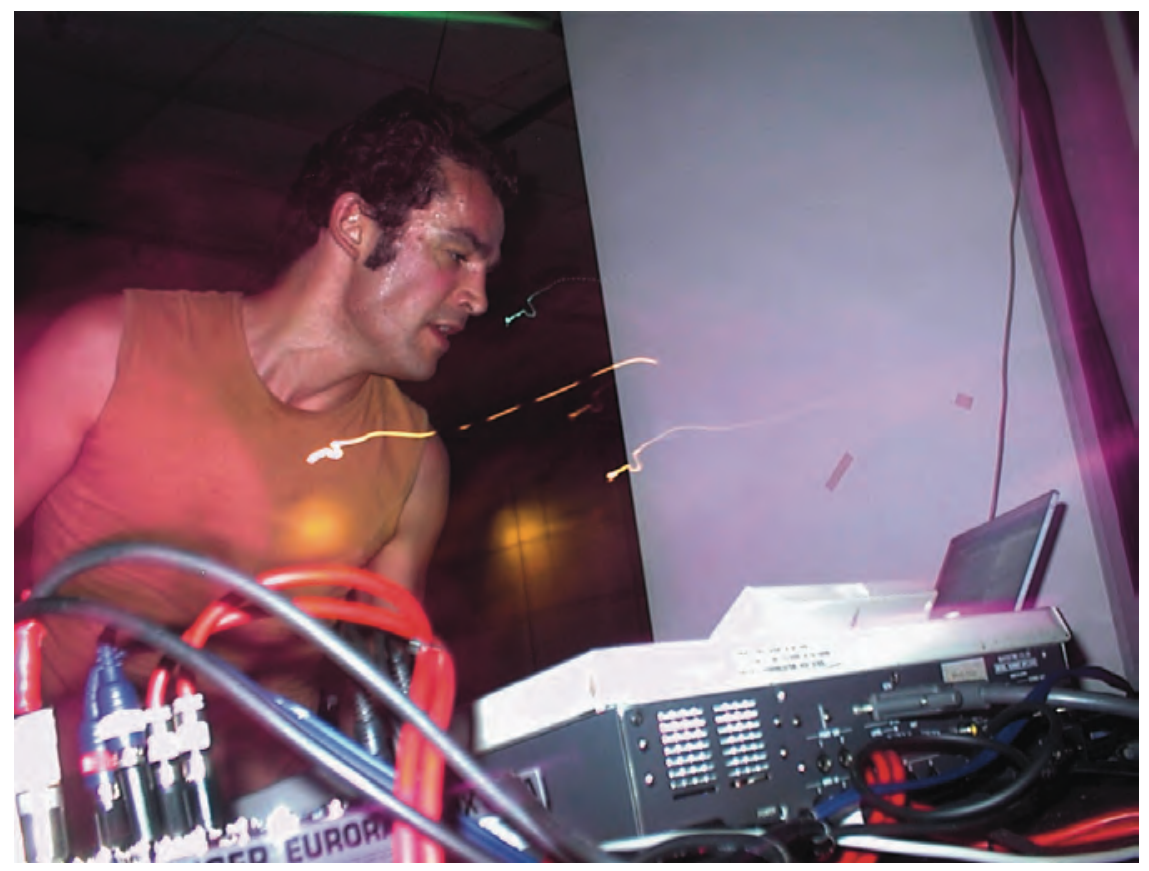

Dandy Jack sweating out a new sound @ MUTEK 2002. Photo: tobias c.van Veen

MUTEK was integral during this period of 2000-2005 in generating a community of producers within the city of Montréal, consisting of artists who gravitated to the city from elsewhere, in part because of MUTEK (such as Mike Shannon, The Mole, Mitchell Akiyama, Deadbeat, Tim Hecker and Jeff Milligan, among others) as well as supporting the locally raised (such as Vincent Lemieux, Skoltz_Kolgen, Martin Tétreault, Akufen, Ghislain Poirier and Egg - among many others). The festival provided an atmosphere in which the continuing evolution of techno, house, electro and dub in its aesthetically complex forms, including those that are complex by way of their reductive strategies in sampling, tonality and rhythm, such as trends in minimalism (minimal techno, microhouse, glitch, etc), were given the time and space in which to germinate. In this respect, we can imagine that MUTEK's inception resonates with the programming activities of The Kitchen in NYC under avant-garde composer and leftfield disco producer Arthur Russell (1974-1975), who much to the chagrin of the "serious" Downtown minimalists, invited in bands such as the Talking Heads and Modern Lovers.

Unfortunately, and unlike NYC, Montréal remained unable to sustain a thriving electronic music scene year round. From 2004 onwards, many of the city's talents moved on to the global focal point of Berlin. At some point, nearly inaudible between 2006 and 2008, MUTEK had shifted its focus from a "festival for producers by producers" to an extended shindig that embraced both moments of sober sonic contemplation and dance floor jouissance. In short, by the time 2009 rolled around, MUTEK realised it no longer had to prove itself; its sonics and visual aesthetics had become successful as both art and revelry. And the same thing was happening elsewhere, with the minimalist and new sounds MUTEK championed - as we heard in 2002 on a bleary Monday morning - now branded "Minimal", coinciding with the post-raver generation's rediscovery of hedonism. MUTEK became a full-on festival of 
psychedelic technohipsters. Nowhere was this more vibrant than at the outdoor collaboration with Picnik Electronic in Parc Jean Drapeau, which, by the standards of North American cities, is a veritable sonic insurrection, Temporary Autonomous Zone or at least immoderate and public gathering of dance floor hedonists (see this video of Picnik to get a sense of MUTEK's soniculture).

\section{http://www.youtube.com/watch?v=bYa-YFwK1Gc}

\section{The axes of MUTEK: global invention \& psychedelic accelerant}

The outlook of MUTEK has been inventively global. As Mongeau has recounted, ${ }^{15}$ the festival developed along two geographic axes, one north-south, between South America and Montréal (specifically Chile), and one east-west, between Montréal and Berlin (the Club Transmediale festival in particular). Satellite MUTEK festivals were established in Mexico, China and Chile, with events now taking place in Southern America and tours throughout Europe. Perhaps the one artist that embodies something of these axes, as well as the range of sonic styles noted above - though on the rhythmic, beat side of the spectrum - is that of Chilean-born, German-raised Ricardo Villalobos, whose particular experiments in house and techno minimalism accelerated the genre precisely at the moment when its dry abstraction risked aesthetic collapse. Villalobos - along with other artists on the Playhouse label and rougher experiments taking place with "schaffle" rhythms over at label Kompakt Extra (aka Speicher) - shifted minimalism from the play of cyclic and one-bar looped samples that defined Detroit's stamp on minimalist techno into a complex interplay of long-play, linear sonic events set against micro-edits in continuously evolving, looping rhythms, earning the unfortunate nickname (for a while) of "ketamine house." $\mathrm{K}$-house, named for its k-hole style properties of deep meditative sonics laden with subtle yet psychedelic inflections (after the recreational use of the heavy tranquilizer that is known to knock users off their feet into a psychedelic near-coma) is best described by music critic Philip Sherburne who wrote at the time (2005) that "Well, for one thing, techno is getting weirder. Ok, so full-on experimental freakouts are few and far between - this is 'dance music', after all, with an emphasis on functionalism but woozy rhythms, psychedelic detailing, and discombobulating effects are permeating track after track, leaving clubbers' heads spinning like a Leslie".

Contemporary minimalism perhaps starts with Villalobos' Alcachofa (2003), which as Sherburne wrote at the time, "was the first indication that minimal techno and microhouse were going psychedelic". Indeed, not only was techno going psychedelic but its dreamy, k-hole psychedelia signalled a massive resurgence in the sound, to the point where "minimal" became a distinct genre from techno (say, circa 2005). Minimal, eschewing its dry severity and abstract patterns, began to open itself through an aesthetic collage with the genre of trance. Or perhaps it finally opened itself to the "interstellar jazz" and "psychedelic offworld techno" of Detroit's Red Planet series crafted by Underground Resistance's The Martian back in the early 1990s. ${ }^{16}$ Though psytrance and other speed-addicted genres remain quite distinct from minimal's psychedelia, this descendent of the time when techno and trance were indistinct has embraced something of the psychedelia as well as the hedonism of the trance aesthetic, while retaining a distinctly slower BPM, deeper (and for the most part) more inventively sampled sonic palette and cross-genre borrowings with house, dubstep and dub. ${ }^{17}$ 


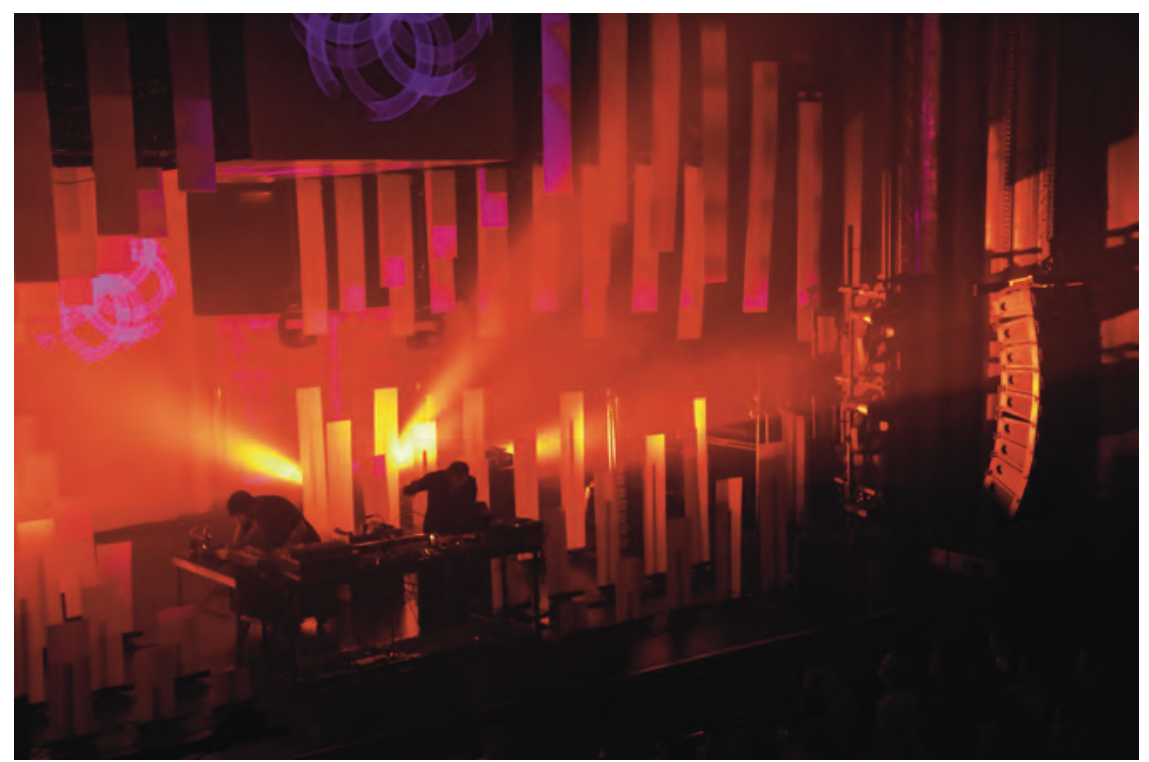

Psychedelick-house: Mathew Jonson \& Dandy Jack@MUTEKX (2009). Photo: tobias c.van Veen

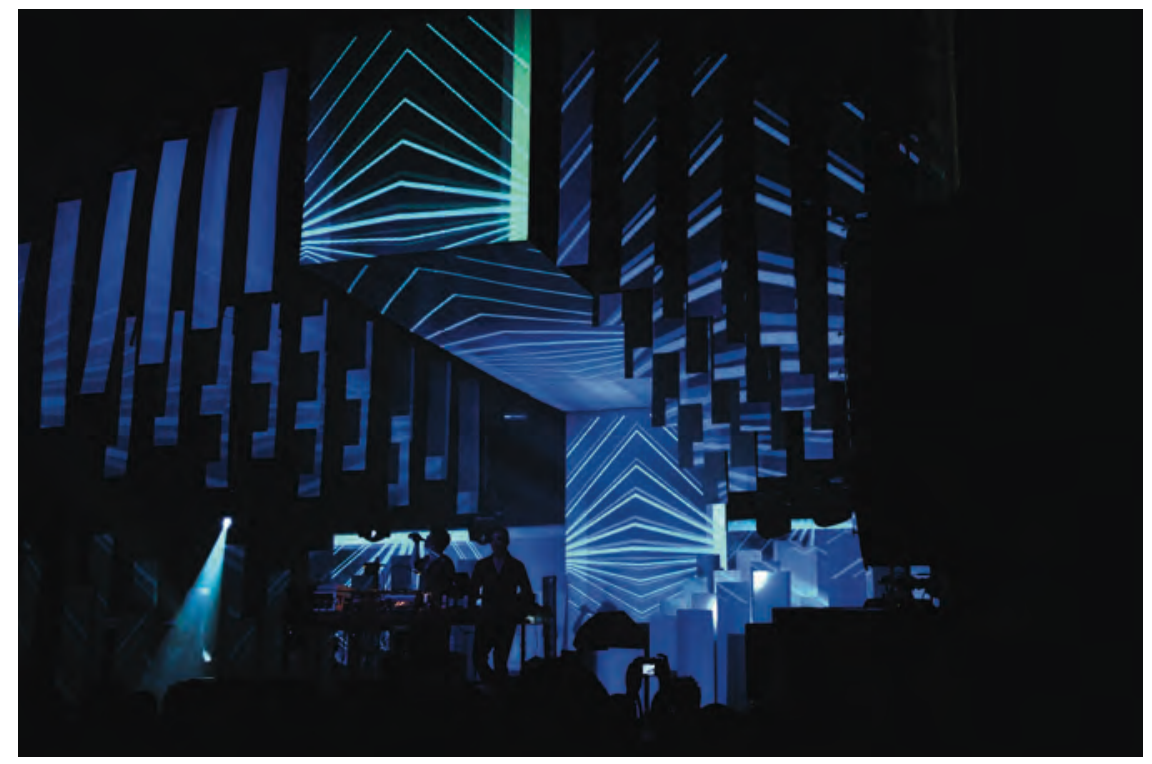

Minimalism goes psychedelic: Mathew Jonson \& Dandy Jack@ MUTEKX (2009). Photo: tobias c. van Veen 


\section{Dandy Jack + Mathew Jonson @ MUTEK 2009}

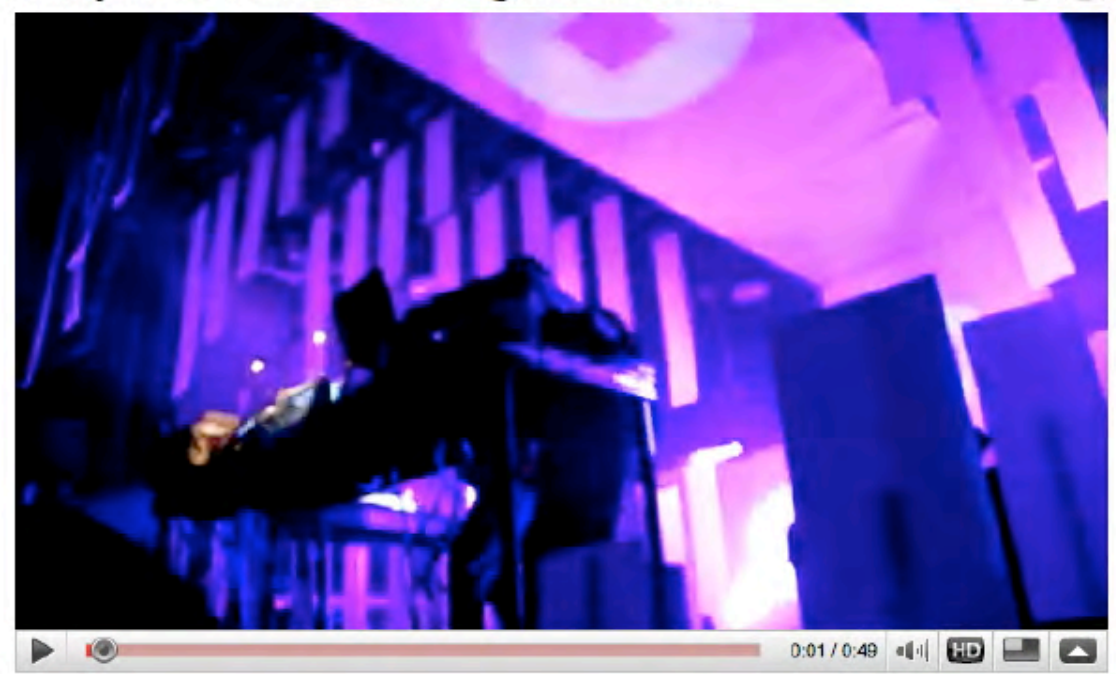

http://www.youtube.com/watch?v=otIKEYcHsps

And so I think it can be said that one axis of MUTEK, despite its reputation as an urban festival, a gathering of bourgeois techno-hipsters, of the post-net-art digerati, of the geeks who don't dance, of those into the very furthest reaches of the (un)listenable, as a festival where producers watch other producers hit play on a laptop - and it is all these things as well - MUTEK is also, if not first and foremost these days, a strangely hedonist and psychedelic gathering. A breed of urban psychedelic culture, too aging to be young hipster, too cynical to be New Age post-raver, too educated to be anything else.

Which is where we get to culture, and where we arrive at in 2009, and the question I have been posing to myself in regards to the C - Culture - in EDMC: if psytrance currently has the edge on other forms of electronic music culture insofar as psytrance festivals remain the largest, if not most intriguing, gatherings of dance music culture - insofar as trance comprises a supranational, willing-to-travel supranetwork of dedicated participants, with larger goals within the gathering, from transcendental dance experience to the healing arts and permaculture as integral aspects of its culture (such as Portugal's Boom Festival) - techno's movement into psychedelic minimalism, and willingness to embrace radically divergent strains of sonic listening, from noise to silence, keeps the edge in pushing sonico-aesthetic boundaries. But with a common denominator of psychedelia - and this remains to be thought, what, precisely psychedelia has come to mean in this context, for it can neither be reduced to the biotechnology of ingested substances nor to clichéd cultural references of tie-dye and the 1960s, and certainly not to variants of New Age mysticism, as the urban technoheads demonstrate - the chance of techno and trance converging comes to the fore. And if this moment comes about, would it not approach something more apt to be signified as a culture, if such a convergence took place, at a time and place? Such a convergence would indeed be something of the mix that brought about acid house and rave culture in the first place, when the gay house circuit began to dance to the harderedged sonic experimentation of acieed, thus attracting white disenfranchised postpunks high on Afrofuturist technomythos willing to embrace the nomadic lifestyle 
of UK travellers (and so on): this kind of crossbreeding is what brings about fertile cultural convergences.

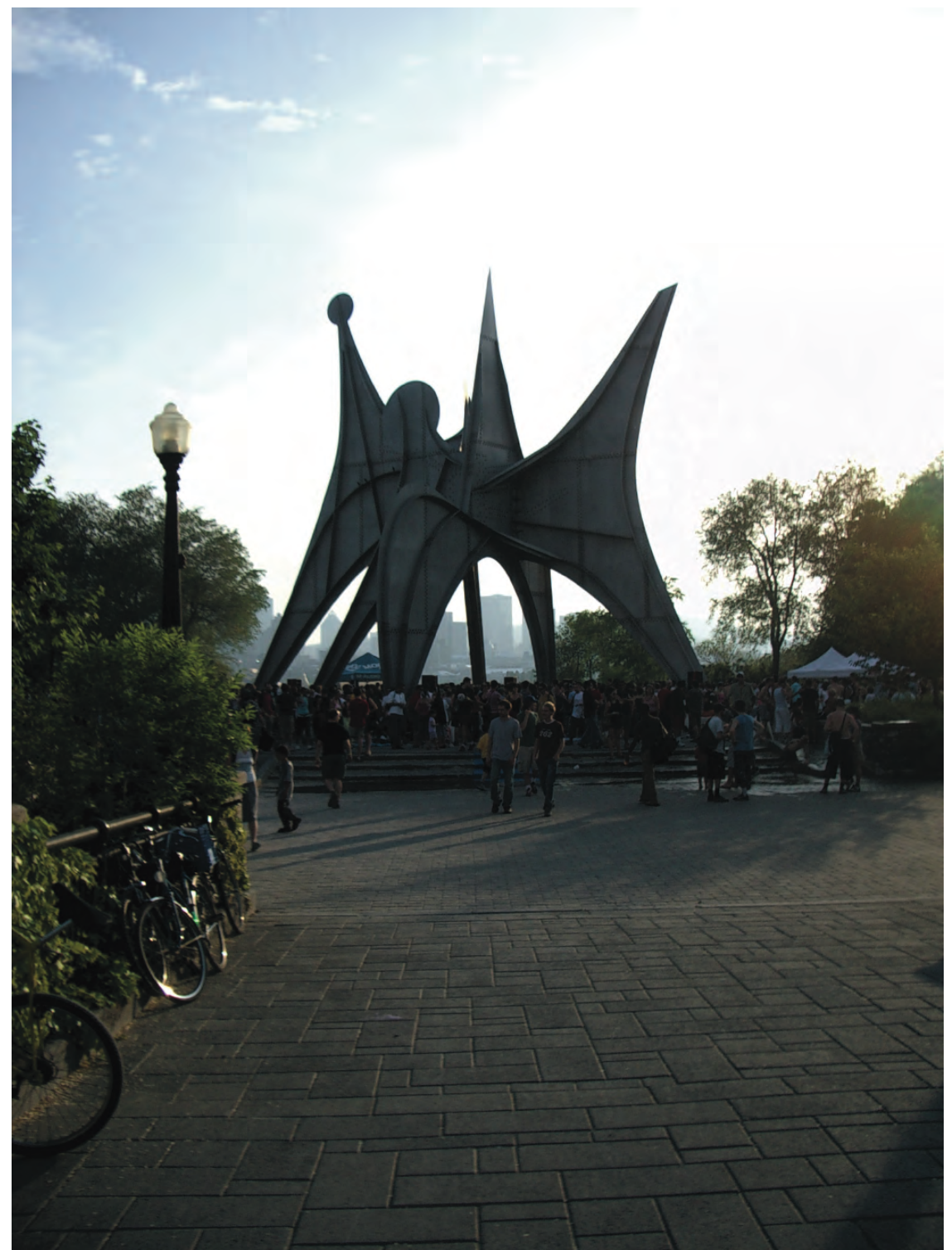

MUTEK converges with public art: Picnik Electronic, MUTEK 2005. Photo: tobiasc. van Veen

Back to MUTEK. At MUTEK multiple variables are at play within this question as to whether its festival - which now attracts thousands of worldwide participants, takes place in multiple venues and runs for over seven days - can become a cultural convergence. As a preliminary remark on MUTEK's ability to crosspollinate cultural niches and attract audiences from outside its established scene, the festival has increasingly expanded its public media arts installations and performances, generating a noticeable intervention within the urban fabric of the city with light and sound. 
In 2009, MUTEK's mark was left on the city in the form of public performances and projections:

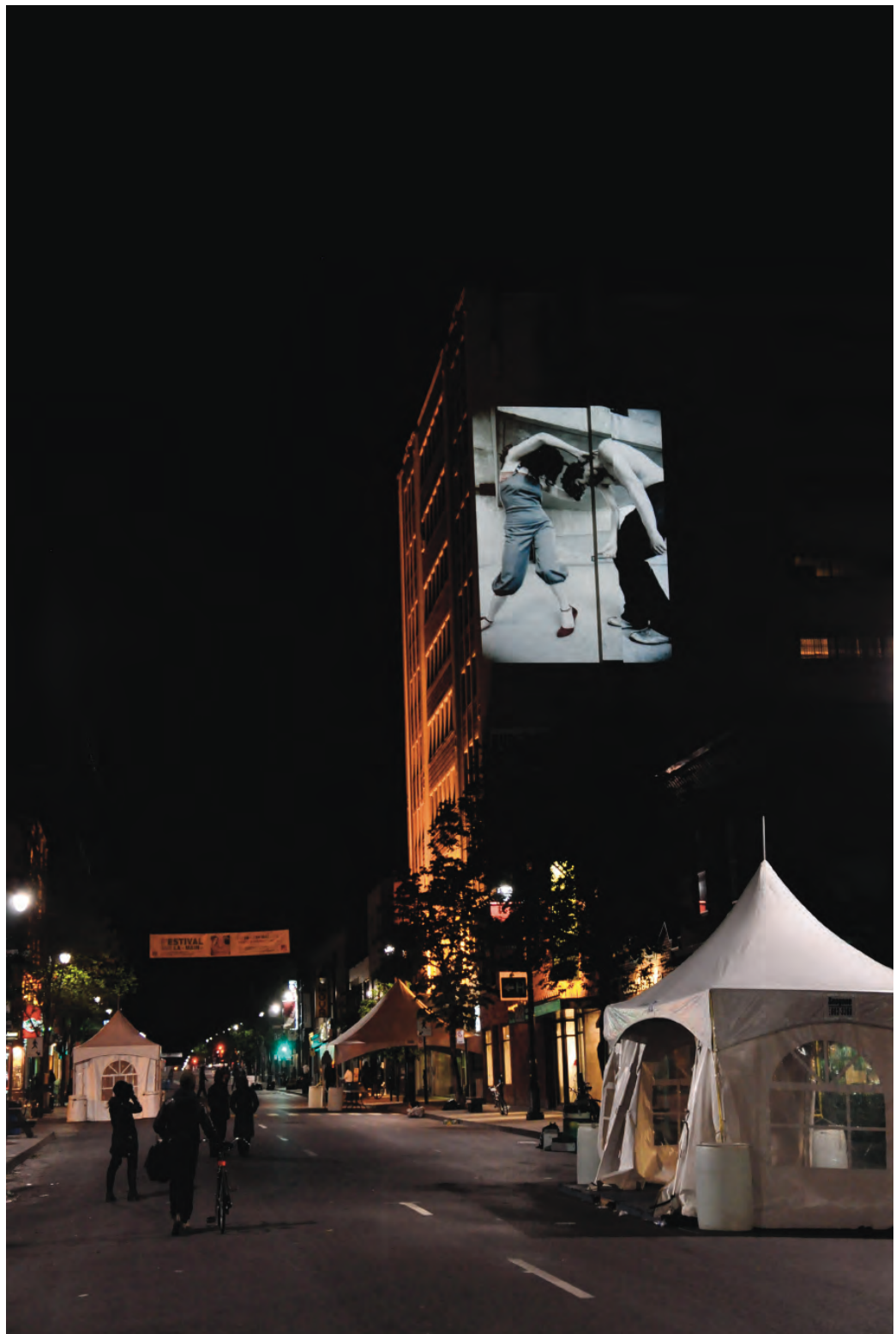

Dominique Skoltz (photo animation) on St. Laurent, MUTEKX (2009). Photo: tobias c. van Veen

The role of technology in a possible cultural convergence affects all aspects of psychedelic soniculture - insofar as technology concerns the nature of performance itself, of the sonic content, of the ways in which psychedelic soniculture communicates, networks, appreciates art and moves to it. Developments in computing technology have largely overcome the limitations of laptop performance, allowing for expressive gesture in the (re)production of performance. Debates circa 2000 through 
2004 concerning the nature of the "live" have all but been surpassed insofar as technological development has allowed for more expressive intervention in the (re)production of performance. ${ }^{18}$ Moreover the context of performance has changed insofar as its signifiers of authenticity have shifted to embrace laptop performativity, sonic reproduction and the aesthetics of playback. On the one channel, the old signifiers of performative authenticity inherent to pop (such as gesture and the connection between movement and sound) have become banalized as pop embraces the role of electronic reproduction and laptop performance - while oft giving in to ventriloquism - while on the other channel, signifiers of the performer's bodily authenticity have seen their resurgence in electronic performance, as witnessed here in the case of Nôze, who recode rock's authenticity into a drunken stupor of sexual ambiguity much to the crowd's delight at MUTEK's Picnik Electronic in 2008:

\section{http://www.youtube.com/watch?v=a4YyS0cuJEw}

Yet again, the general concert, such as in rock, pop music and hip hop, as well as classical, have all born witness to the entrance of the laptop and the onstage performance of the laptop itself, from Radiohead's Kid A (2000) to Björk's Vespertine tour and album (2001), with production by experimental house music artists Matmos and Mathew Herbert. And of course, we do not even mention that the question of performative authenticity rarely dogs the prerecorded and prerehearsed performances of contemporary pop music, such as Britney Spears. Only in a contracultural dimension of "real" music, such as indie or techno, is the question of authenticity at all contemplated - at least since Milli Vanilli.

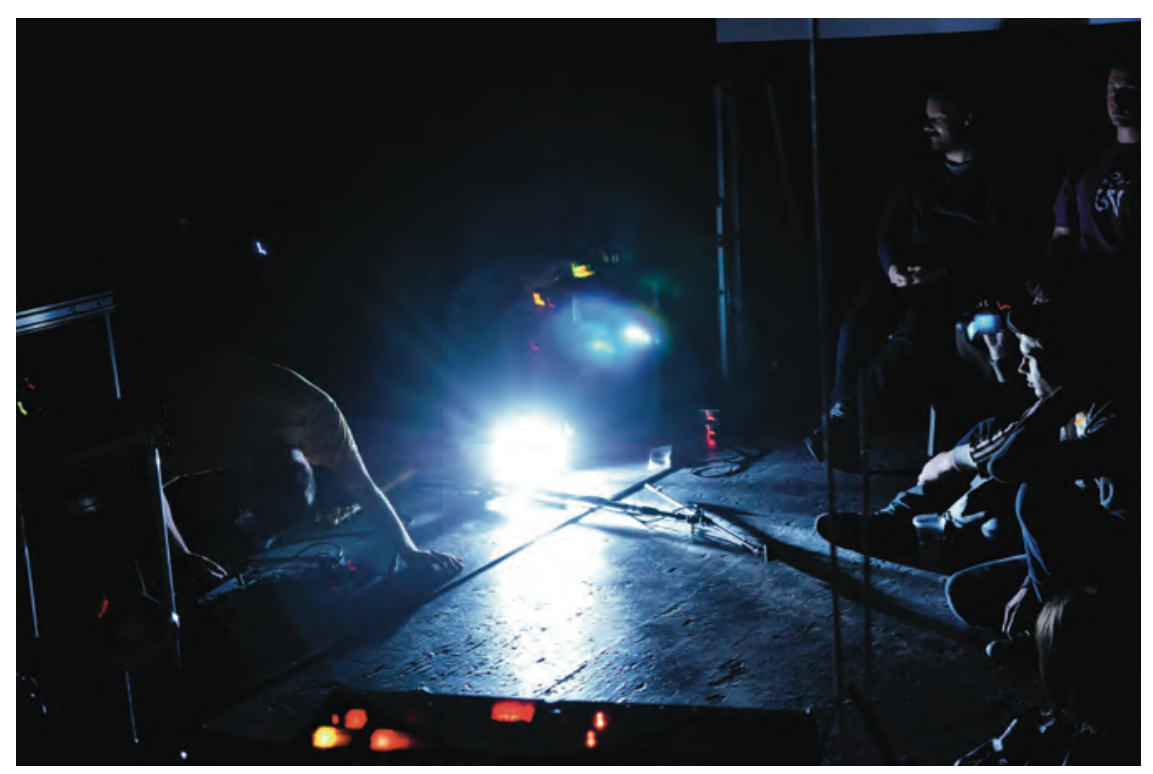

Beware the artists: strobe noise @MUTEKX (2009). Photo: tobias c.van Veen

The second variable to a cultural convergence is that of the performative geography of the festival itself. In what kind of venues does MUTEK take place? The Parc Jean Drapeau gatherings of Picnik Electronic held under a giant Alexander Calder statue entitled "Man" (built for EXPO '67) and the open-concept events at the Society for 
Arts and Technology allow for self-made, participative audiences that get-in on the event, becoming part of a festival ritual, an upending carnival and a downright shindig. Likewise, the experimental music venues that embrace noise or lo-fi performance - the aesthetic domain of curator Eric Mattson - are often laid out in such a way that the "audience" must self-arrange bodies and ears around the sometimes flailing antics of performers.

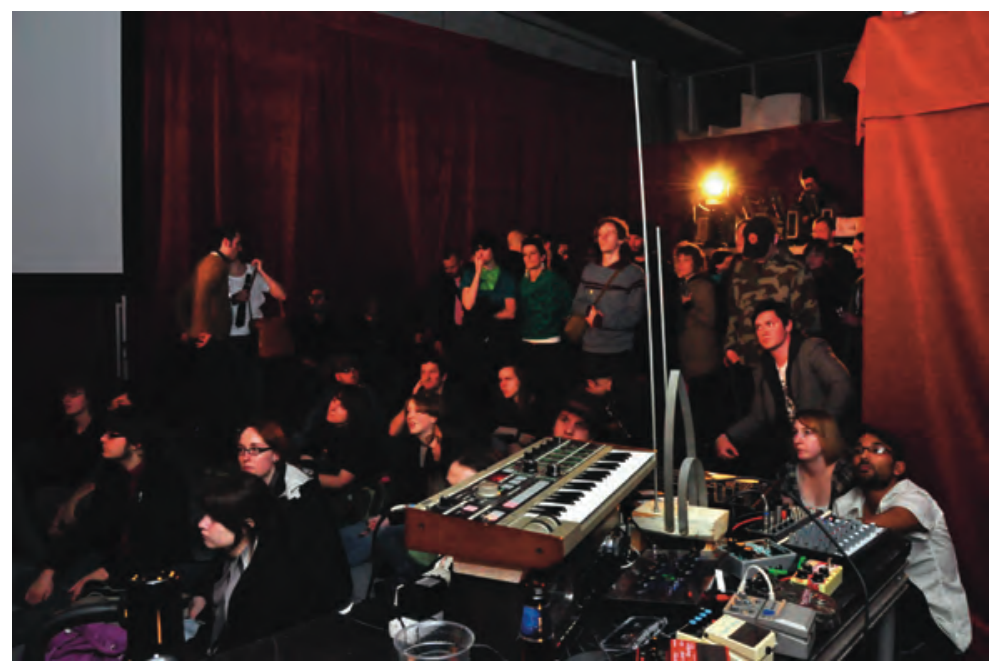

Noise performers \& crowded becoming-ears at MUTEKX (2009). Photo: tobias c. van Veen

Still, seated performance areas have also claimed their own space, as work that cultural elites would deem more "serious" require a focused listening environment where no-body moves (and it is just as elite to critique such listening environments on these grounds). To this effect, audiovisual performances such as GAS, Burnt Friedman and Artificiel took place in a multimedia theater venue of the Monument Nationale:

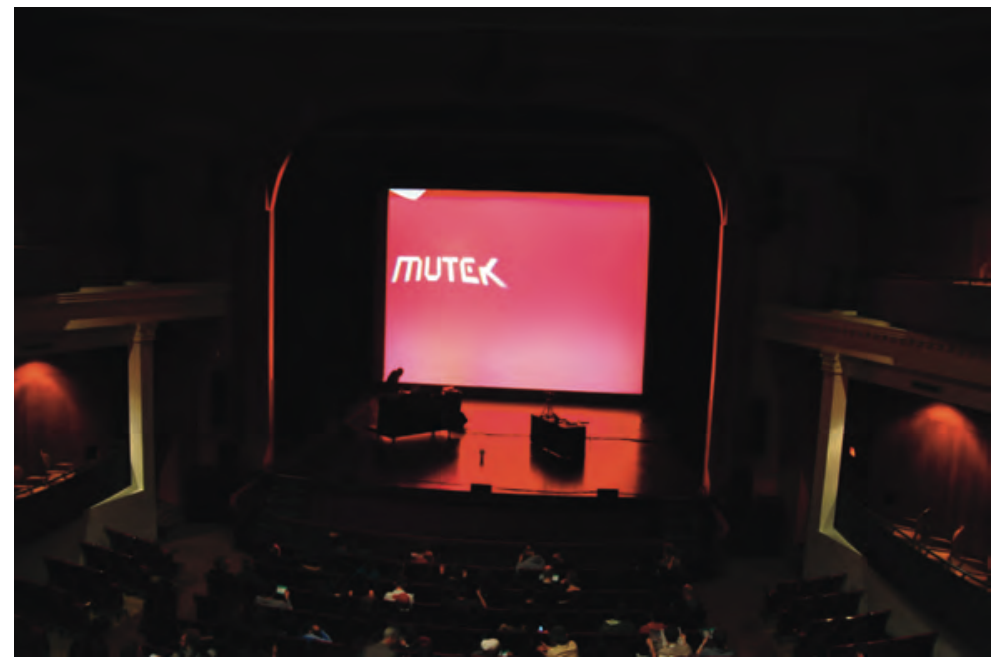

Monument National, MUTEKX (2009). Photo: tobias c. van Veen 
Thus allowing the presentation of work such as that of Artificiel's investigation of a Tesla coil:

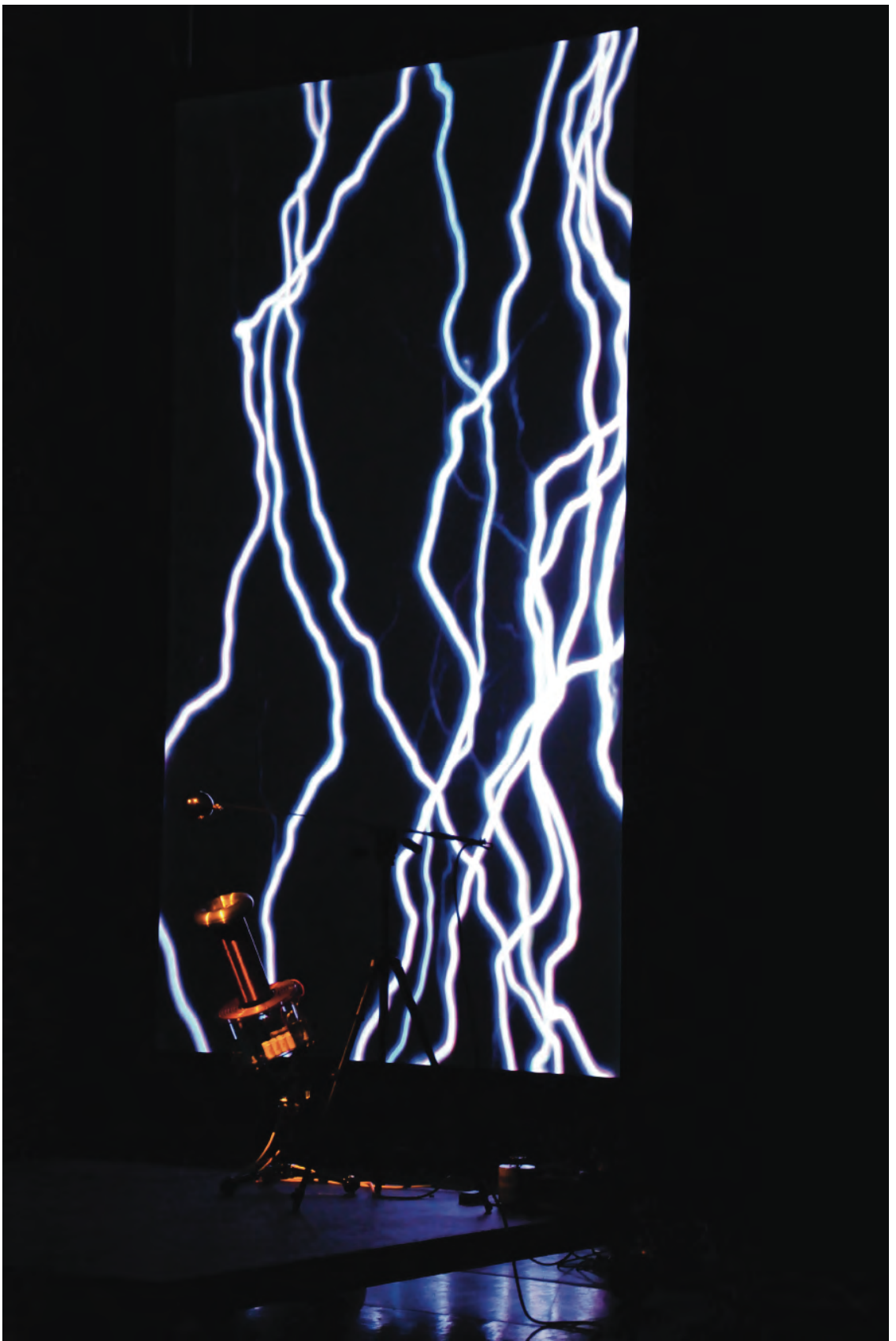

Artificiel@MUTEKX (2009).Photo: tobiasc.van Veen 
Still, the most intimate and barrier breaking of spaces is always the afterparty, here with surprise guest, Chicago house legend DJ Sneak.

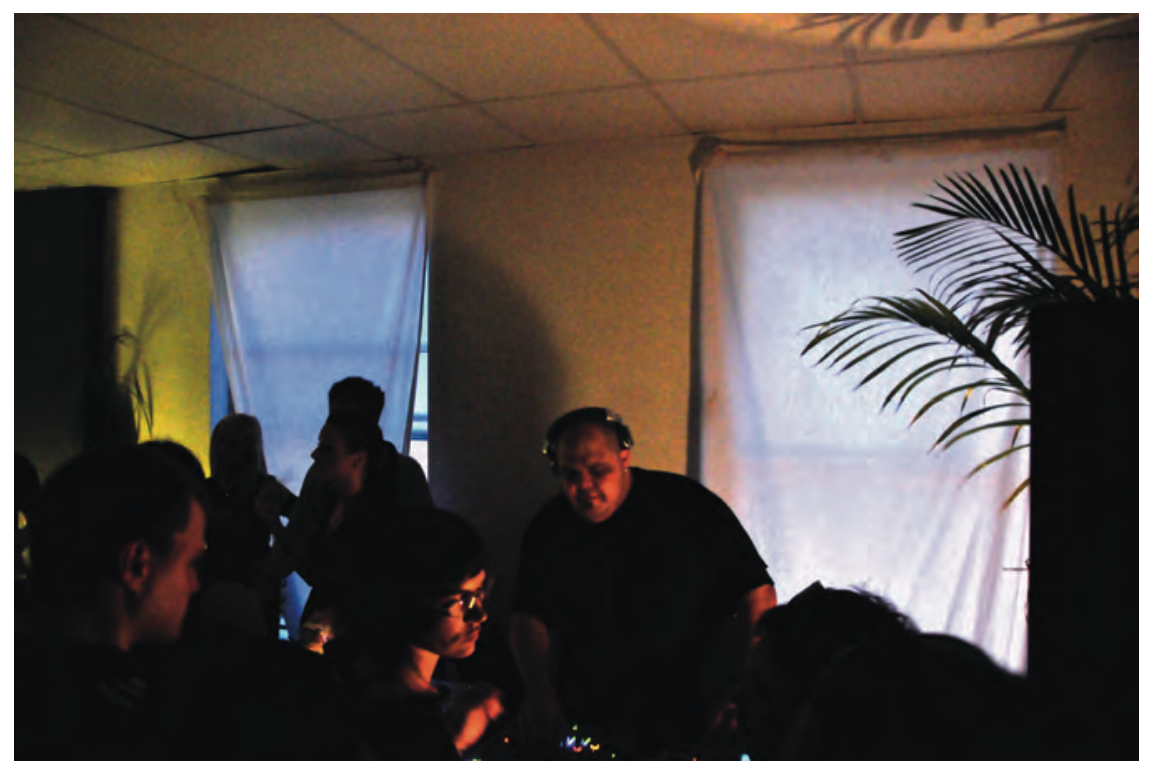

DJ Sneak, 5am-ish, Monday morning, MUTEK X (2009). Photo: tobias c. van Veen

Yet surprises can also arrive with the most intriguing of experimental performance, where stillness encompasses the performer, here New York's o.blaat who works with room performance dynamics. Walking into the alternative room at large-scale concert venue Metropolis, this open-unorganised space (save for a low-riser for the performers) allows interactions such as this:

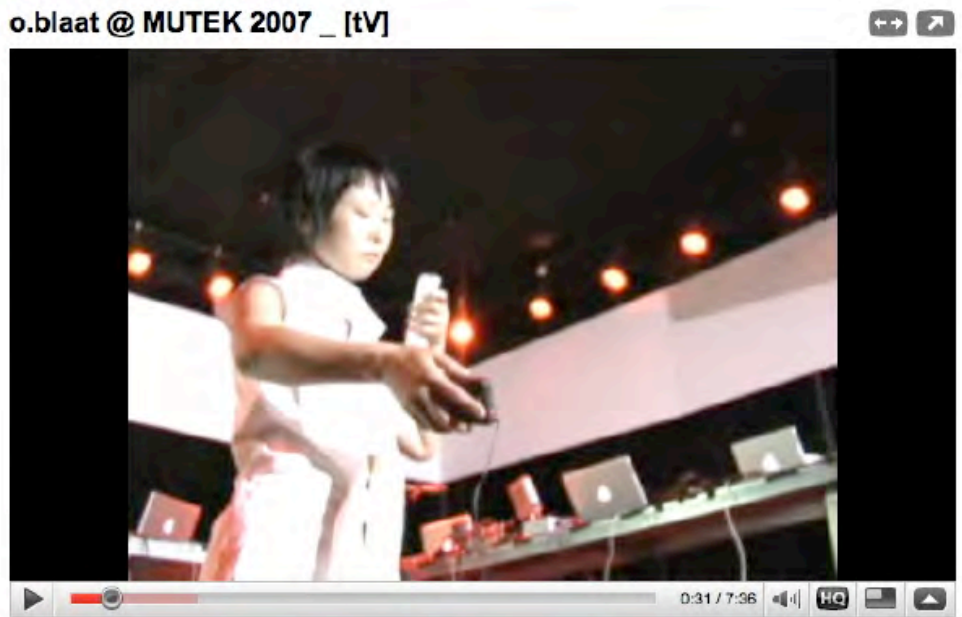

http://www.youtube.com/watch?v=s6i4WTWY1sU

And performers such as Kode 9 and Spaceape, through their sonic force of low-end dubstep, performed by way of turntablism and incantation MCing, allow darkness to 
descend upon an open spatial reconfiguration of the SAT, opening alternative performative mythologies not only onstage but off:

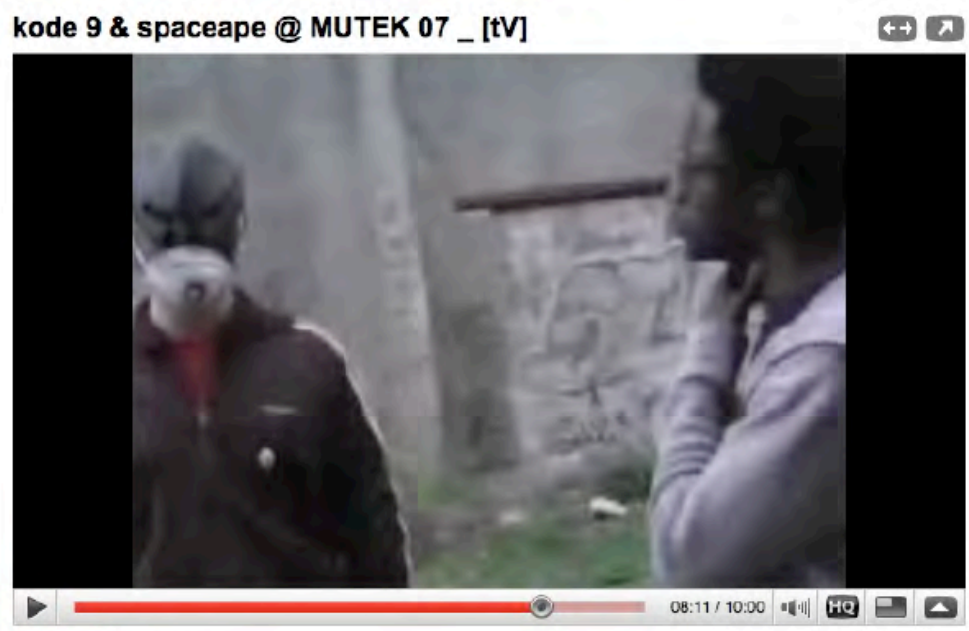

$\star \star \star \star \star ⿱ 亠 乂 .14$ ratings

6,961 views

http://www.youtube.com/watch?v=G0MYajFs3UQ

Yet even with seated venues, the investigation of gesture-based performativity by the artist can generate a new experience, often categorised as "live cinema", insofar as the interpretation of audio-visual events is made apparent, like jazz, and to be found prominently in the work of Skoltz_Kolgen (http://www.skoltzkolgen.com). With audio-visual composer Randy Jones, psychedelia once again comes to the fore, this time in a visual motif that recalls yet hyperaccelerates the liquid oil-based projections of the 1960s alongside sounds closer to Max Neuhaus than acid rock:

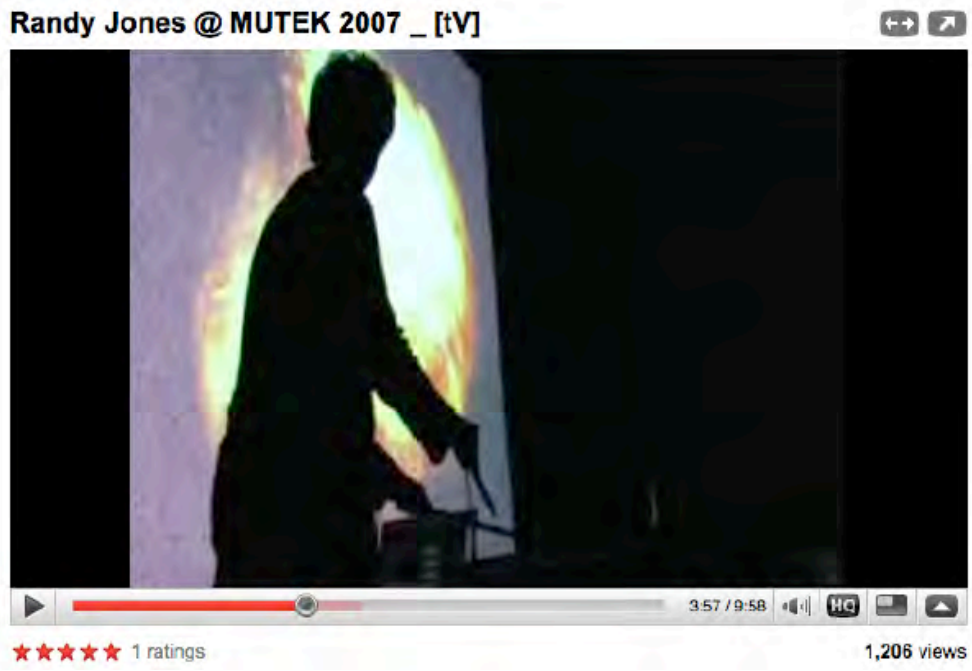

http://www.youtube.com/watch?v=qRn_pozXbWA 
Deep ambient composer Clinker traces psychedelia in not only composition and performance, but in the art of the interview:

\section{http://www.youtube.com/watch?v=nj-ffuoHvZA}

In all of these spaces, sounds and sights reconfigure the audience into either experiencing coordinates in listening and seeing that are far from the everyday - or refract the everyday into a focused environment. Whether this audience is seated in a mesmerised sonic trance or joyously whooping it up at Picnik (even going strong in the rain these past few years), the conditions for a shared experience exists - a convergence of otherwise unmet bodies. And - or at least it is my loose hyperthesis that a form of psychedelia, technological in nature, is providing the impetus for all of this happening. Where the everyday is already permeated with an intense level of technological substrate, of interconnective messaging, cellular telephonic activity, and the forever-online world of the urbanite, it has become near banal that the psychedelic experience of fractal distraction in perception is commonplace (at least in the busyness of urban centres; yet all computerised life subsists in this fashion). Taking sonics and visual arts that embrace and investigate the (a)rhythmic interplay of this technoworld is part of the underlying soniculture's contribution to aesthetically enjoying the world as well as providing the models and means of communitas for this kind of world experience to take place. And this taking place is embracing an undercurrent of psychedelia. ${ }^{19}$

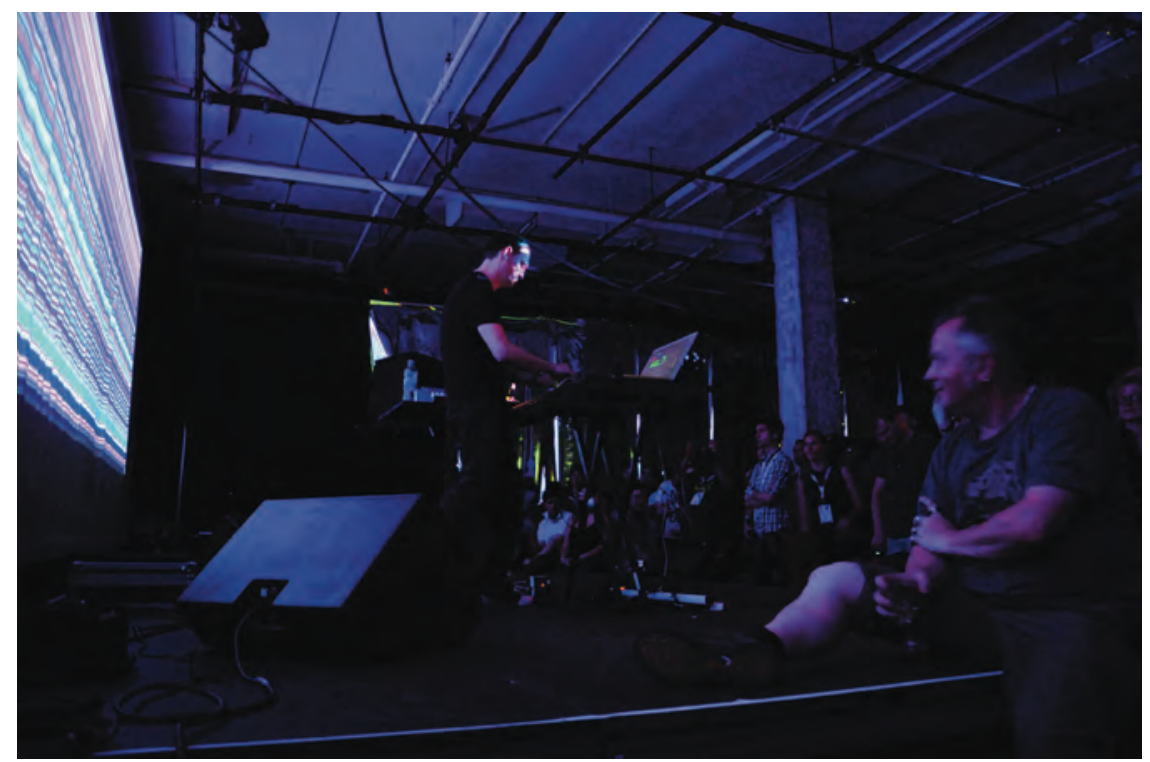

Psychedelic minimalism: Carsten Nicolai @ MUTEKX (2009).Photo: tobias c. van Veen 
Nowhere was this celebratory psychedelia felt more than through the exemplary visual projections at the Metropolis venue. Metropolis, a classic two-level theater retrofitted to concert venue and dance haven, holds several thousand people with a full wooden dance floor, professional bass-laden sound system and upper balcony level, thereby allowing an interplay between rest and dance, spectatorship and participatory circulation. With the near church-like atmosphere created during Carl Craig's set, psychedelia took hold from the first sounds of Detroit's second wave:

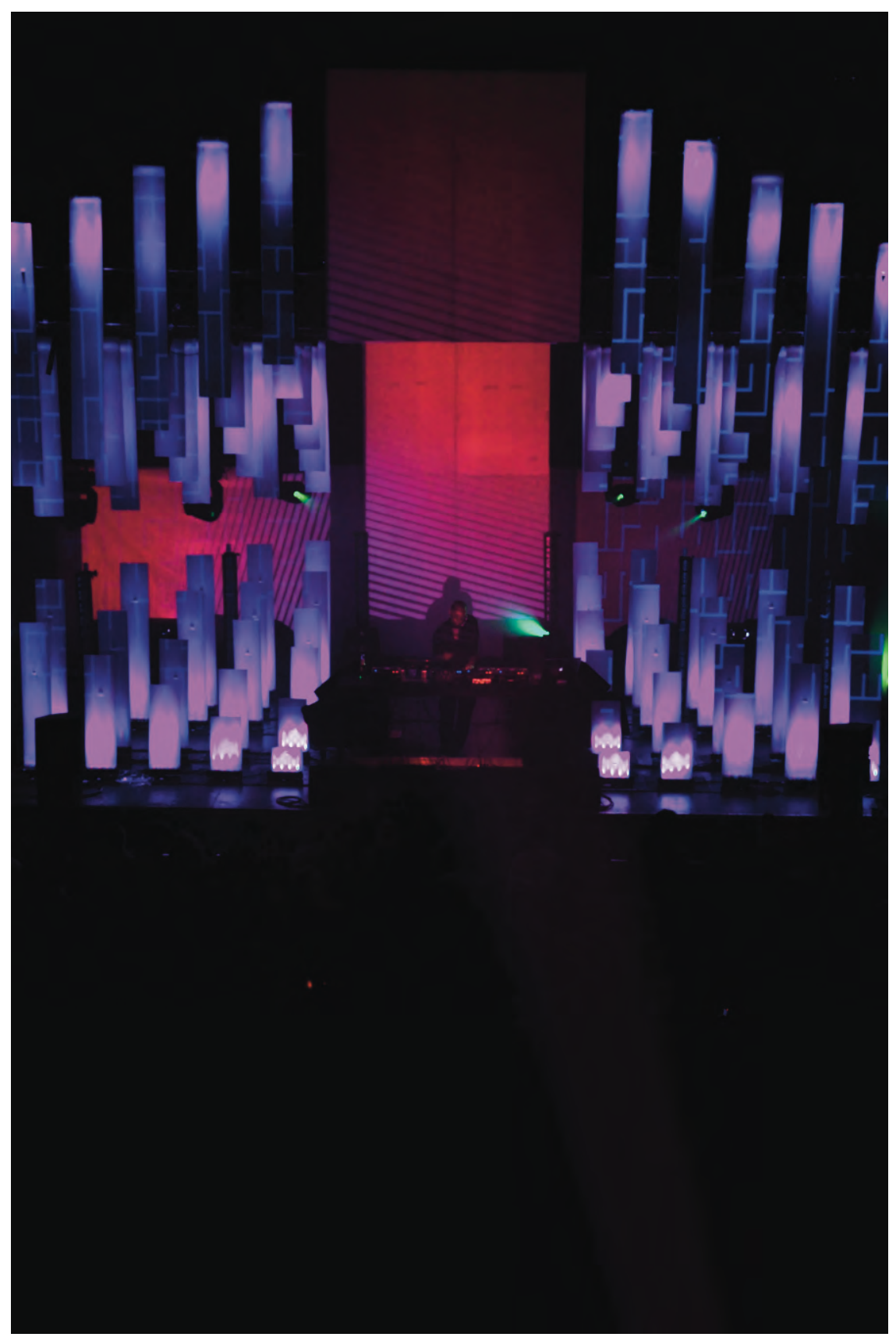




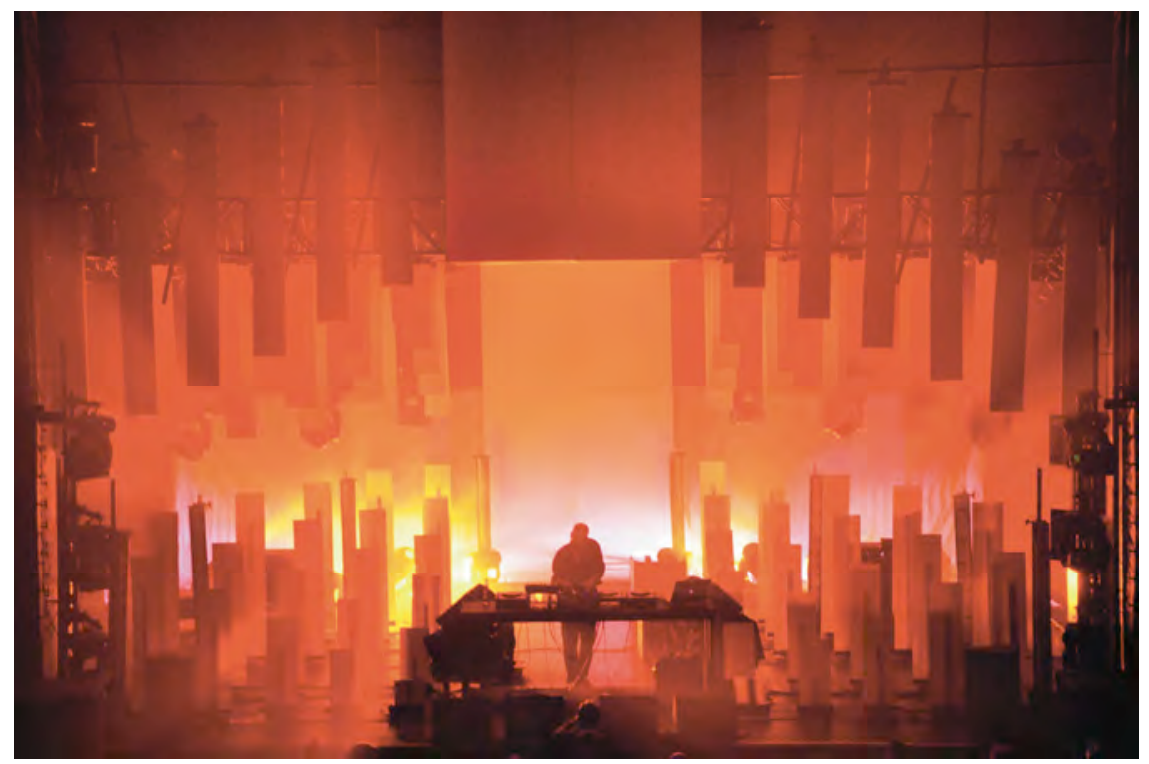

CarlCraig@MUTEKX (2009).Photo: tobiasc.van Veen

http://www.youtube.com/watch?v=oCX0Hvt06BI

Leading audiences into a purple haze atmospherics of sonic immersion and bodily proximity that can only be emphasized as the basis for peaceful coexistence amongst an antagonistic species:

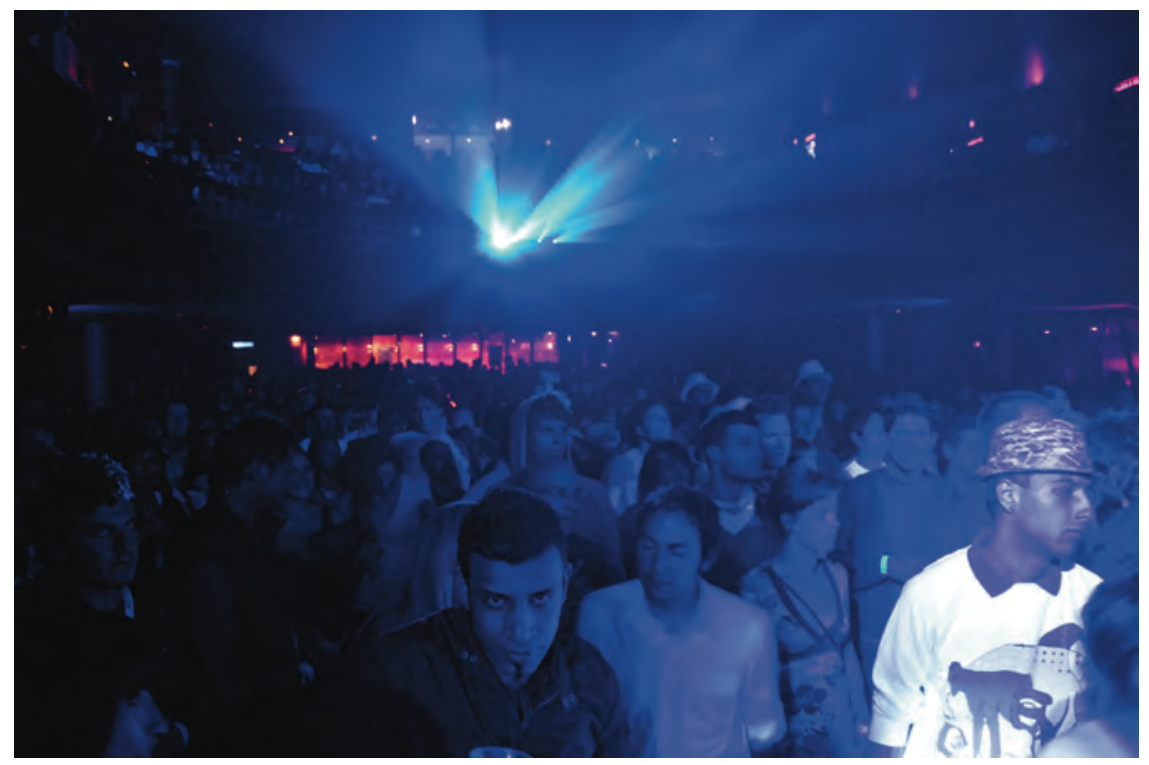

The purple haze, MUTEKX (2009). Photo: tobias c. van Veen 
To return to our first question, can MUTEK's soniculture be considered an EDMC?

Only insofar as the terms are placed under a certain erasure and remixed to what has become of soniculture in the 21C: psychedelia. And it is psychedelia that offers the potential for a cultural convergence, for an unmet interplay between sonics and aesthetics, bodies and trajectories of travel. Would the electron-culture converge once again into a diverse massification capable of the energies unleashed in the late 1980s, perhaps a startling connected and as of yet unheard constellation will come into play within this world, one in which a connection / convergence to its history, yet also to its selves, remixes the ancient motifs of psychedelia and ritual.

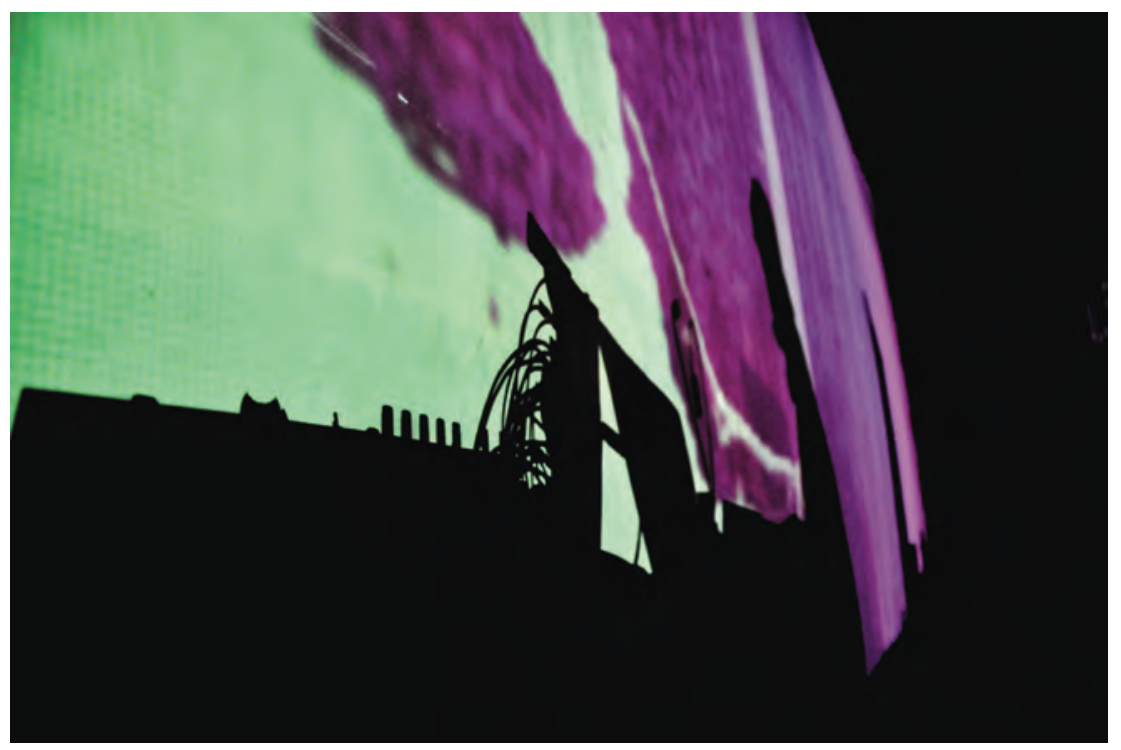

Cobblestone Jazz adds Colin the Mole to become the Modern Deep Left Quartet: Canadian techno minimalism has always been psychedelic, indeed. MUTEKX (2009). Photo: tobias c. van Veen

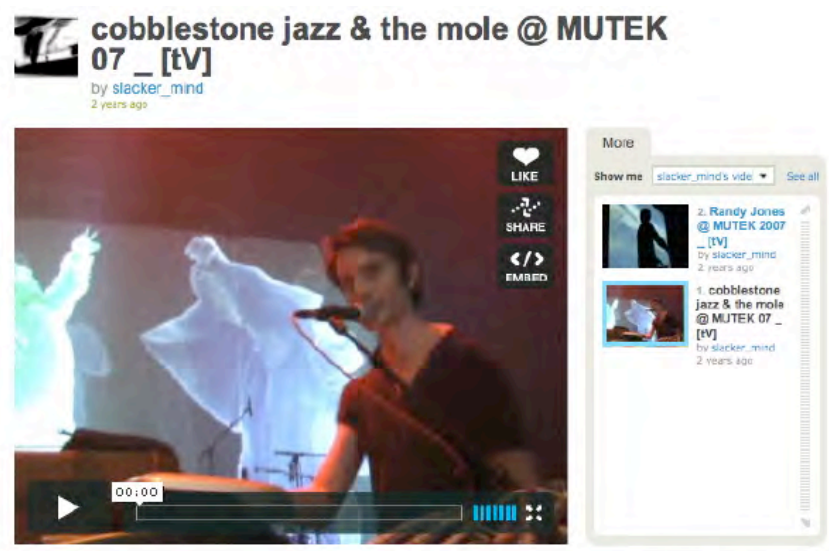

Cobblestone Jazz and Colin the Mole live at MUTEK, June 1st 2007, Montreal. Captured by tobias c. van Veen _ quadrantcrossing.org. Thanks to the Garden City Dubs crew for doing what they do best.

\section{http://vimeo.com/205146}

Cobblestone jazz \& the Mole@ MUTEK 07,from Slacker Mind 


\section{References}

Cage, John. 1973. “The Future of Music: Credo". In Silence: Lectures and Writings by John Cage, pp. 3-7. Hanover: Wesleyan University Press.

Cascone, Kim. 2002. "Laptop Music - Counterfeiting Aura in the Age of Infinite Reproduction". Parachute: electrosons_electrosounds 107: 52-60.

Gibson, William. 2008. Spook Country. New York: Berkley.

Sherburne, Philip. 2002. "Finding A New Genre At MUTEK". Needle Drops June 7, 2002: < http://www.neumu.net/needledrops/data/00040 needledrops.shtml>. Accessed 20 August 2009.

----. 2005. "The Month in Techno". Pitchfork 27 September, 2005: $<$ http://pitchfork.com/features/techno/6153-the-month-in-techno/>. Accessed 20 August 2009.

van Veen, tobias c. 2002. "A Fine Marriage of Madness and the Margins at Mutek 2002". The Wire 222 (August). Archived at: $<$ http://quadrantcrossing.org/papers/Mutek2002-Wire-tV.pdf $>$. Accessed 20 August 2009.

----. 2002a. "Bleeps in the Heart of the Beast - MUTEK 2002 in Montreal". Discorder (July). Archived at: <http://quadrantcrossing.org/papers/Mutek2002-Discorder-tobiasv.pdf>. Accessed 20 August 2009.

----. 2006. "Kompakt \& Recycle", Kompakt 6: 54-6.

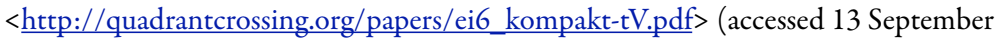
2009).

----. 2009. Forthcoming. "10 glitches in the failure of microsound". Which was to be published in Kim Cascone (ed) Vague Terrain: Microsound 15: <http://vagueterrain.net $>$. As Cascone made last minute changes without consulting the authors, now we'll see.

\section{Discography}

Minilogue. Animals. 2008. Cocoon (LP, CD): COR LP 016, COR CD 016. http://www.discogs.com/Minilogue-Animals/master/33266

Villalobos, Ricardo. 2003. Alcachofa. Playhouse (LP, CD): PLAY083, Playhouse cd08. http://www.discogs.com/Villalobos-Alcachofa/master/11385

\section{Author Biography}

tobias c. van Veen is a renegade theorist \& practitioner of the technology arts. A techno-turntablist and instigator of sonic interventions since 1993, tobias is doctoral candidate in Philosophy \& Communication Studies at McGill University. His next publication, an edited volume tentatively titled Afrofuturism: Interstellar Transmissions from Remix Culture is forthcoming from Wayne State UP, 2010. He also mixes a mean absynthe martini. His research blog can be found at:

$<$ http://fugitive.quadrantcrossing.org/> 


\section{Notes}

1 I write "21C" as the century is more or less encoded in bits and bytes.

2 As I write elsewhere (van Veen 2009, forthcoming), let us grant Cage his due with his realisation, as early as 1937 - though "early" only by virtue of a white modernist history that rhythm and percussion, in the deconstruction of tones and scripts, "explores the academically forbidden 'non-musical' field of sound," and that an Afro-American tradition of "hot jazz," if not one of "Oriental cultures" in general, where "any sound is acceptable," has already "transitioned" from "keyboard-influenced music" to "the all-sound music of the future" (5).

3 Specifically, in Spook Country (2008).

4 See MUTEK: < http://mutek.org/> (accessed 20 August 2009).

$5 \quad$ See "An Endless Urban Festival" at Tourism Montréal:

$<$ http://www.tourisme-montreal.org/Press/Itineraries-by-theme/Events-and-Entertainm ent $>$ (accessed 20 August 2009).

6 One is reminded of the way in which the world's cities have signified their essence: Paris is the City of Light, Chicago the Windy City, Philadelphia the City of Brotherly Love, New York the City That Never Sleeps (and perhaps London is, with some resignation, simply the grey and rainy one). Montréal, as the City of Festivals, is perhaps among the first to brand its essence by way of a Tourism organisation.

$7 \mathrm{FCM}(\mathrm{M})$ has since dropped the 'New Media' component. See "FCMM": $<$ http://www.fondation-langlois.org/html/e/page.php?NumPage=114 $>$ and <http://www.nouveaucinema.ca/ > (accessed 20 August 2009).

For a visual analysis and conference comments concerning MUTEK's changes circa 2006, see "MUTEK 2006: Velvet Panda Meets tobias c. van Veen", posted to YouTube.com, May 31st 2006: <http://www.youtube.com/watch?v=11gY2Du5D9U> (accessed 20 August 2009).

9 See "The Society for Arts and Technology (SAT)": $<$ http://sat.qc.ca/ $>$ (accessed 20 August 2009).

See "Ex-Centris": < $<$ http://www.ex-centris.com/> (accessed 20 August 2009).

See "MUTEK Grows Older and Wiser", posted to XLR8R TV on August 5th, 2008: $<$ http://www.xlr8r.com/tv/67> (accessed 20 August 2009), 2:20 - 2:50.

See "MUTEK Grows Older and Wiser", posted to XLR8R TV on August 5th, 2008: $<$ http://www.xlr8r.com/tv/67> (accessed 20 August 2009), 3:00 - 3:10.

Save for, of course, resolute experimentalists such as Janek Schaefer and Martin Tétreault, who use the turntable as a performance object rather than a mixillogical tool. See van Veen $(2002 ; 2002 a)$. Notably: "It was the final Sunday performance that served as an apostrophe for the question of the live and the absence of a member of electronic music's history up to this point: the DJ. [...] The DJ, as a purveyor and selector of musical memories and a distinct link to electronic music's Afro-American histories, is a distinct component that could well combat experimental electronic music's current sense of stagnation [...]. It was not through the DJ that this musical critique was carried out; instead, it was through the DJ-gesture of the sadomasochistic jam-session between Ricardo Villalobos, Dandy Jack, and Atom Heart that revisited the core elements of repetitious dance music in the territory of the mix, exploring territories of techno, electro, and the dark heart of minimalism. [...] It was a supremely disjointed moment when Mutek not only felt (and once again) out-of-time and in conflict with its representation, but pursuing perforated points of sonic ecstasy". 
$14 \quad$ See van Veen (2002a): “The whole thing was only to be topped with the mindfuck that followed: a gear-jam between Dandy, Atom, and Villalobos...starting at 2am thereabouts, it moved into the pounding and one-bar loops of hard techno, but always with this strange funked edge, cutting into electro, and then building back into the 4/4...somewhere along the way it became relentless, and vicious. Sadomasochistic. Suddenly Mutek made sense. It all became clear again. I pulled out my notebook and began to write $[\ldots]$ Mr. Baphomet tells me that he has not seen anything like this since Richie Hawtin and Jeff Mill's Sickness party. This is where we are at. An un-named journalist from San Francisco has just offered me a bowl and we are going to lie back and listen as our minds and bodies and legs are too tired to do anything else...”. In various interviews with the author, 2001 - 2009. In particular see "MUTEK Grows Older and Wiser", posted to XLR8R TV on August 5th, 2008: <http://www.xlr8r.com/tv/67> (accessed 20 August 2009). See The Martian: <http://www.discogs.com/artist/Martian\%2C+The $>$ (accessed 20 August 2009).

For more on the relation between techno and trance, insofar as trance remains in some respects the final frontier of techno, see van Veen 2006; for an exemplary act that crosses trance and minimal, see Minilogue's 2008 release, Animals Concerning such debates, see Cascone (2002). It's worth watching these 2007 videos of Richie Hawtin, DJing at Terrace / Weekend club in Berlin, and listening to the psychedelic detail of minimalism's sound design, all at a heartrate BPM and without need of clichéd build-ups or overplayed, romantic harmonics. See “Hawtin@Weekend", posted on YouTube.com July 9th 2007: < http://www.youtube.com/watch?v=OwriODqTUXQ\&NR=1> (accessed 20 August 2009); and “Richie Hawtin @ Terrace, Berlin 07.07.2007", posted on YouTube.com July 10th 2007: <http://www.youtube.com/watch?v=SewGDnPP9bk> (accessed 20 August 2009). And all this despite the rain. 